International Journal of Advanced Chemistry, 8(1)(2020) $111-117$
International Journal of Advanced Chemistry
SPC
Website: www.sciencepubco.com/index.php/IJAC
Research paper

\title{
Determination and validation of pregabalin in bulk and pharmaceutical formulations by reversed phase-high performance liquid chromatography
}

\author{
D. N. Vidya ${ }^{1}$, R. Chaithra ${ }^{1}$, G. P. Senthil Kumar ${ }^{1} *$, D. R. Bhadresh ${ }^{1}$ \\ ${ }^{1}$ Department of Pharmaceutical Chemistry, Bharathi College of Pharmacy, Bharathinagara, Rajiv Gandhi University of \\ Health Science, Madhur Taluk, Mandya dist., Karnataka-571 422, India \\ *Corresponding author E-mail: drsenn78@yahoo.com
}

\begin{abstract}
A simple, specific, quick, isocratic Reversed Phase High Performance Liquid Chromatographic method was developed and validated for the analysis of Pregabalin in bulk and 5-different pharmaceutical formulations, the separation was accomplished on a C18, 5 $\mu \mathrm{m}$ Reverse Phase column $(250 \mathrm{~mm} \times 4.6 \mathrm{~mm})$ using a methanol : water $(95: 5, \mathrm{v} / \mathrm{v})$ mobile phase. The compound was eluted isocratically at a flow rate of $0.8 \mathrm{ml} / \mathrm{min}$. The UV detector was set at $288 \mathrm{~nm}$ for the detection of Pregabalin (PRG). The method was linear over the range of 5-45 $\mu \mathrm{g} / \mathrm{ml}$ and validated with respect to accuracy, precision, linearity, and specificity, limit of detection and limit of quantization. Robustness testing was also conducted to evaluate the effect of minor changes to the chromatographic system and to establish appropriate system suitability parameters. This method was used successfully for the quality assessment of 5-different pharmaceutical formulations with good precision and accuracy.
\end{abstract}

Keywords: Pregabalin; Isocratic System; Validation; RP-HPLC; Different Pharmaceutical Formulations.

\section{Introduction}

Pregabalin (PRG) is chemically (S)-3-(amino methyl)-5-methyl hexanoic acid and is not official in any pharmacopoeia. Structural analogues of $\gamma$-amino butyric acid (GABA) as shown in (Fig. 1). Nature of PRG is a new anticonvulsant and analgesic medication that was recently approved for adjunctive treatment of partial seizures in adults, and for the treatment of neuropathic pain from postherpetic neuralgia and diabetic neuropathy. The site of action of drug is the alpha 2-delta $(\alpha 2-\delta)$ protein, an auxiliary subunit of voltage gated calcium channels. PRG subtly reduces the synaptic release of several neurotransmitters, apparently by binding to $\alpha 2-\delta$ subunit and possibly accounting for its action in vivo to reduce neuronal excitability and seizures.

There is no any official, sensitive, accurate, precise and chief analytical method developed for the analysis of pregabalin till now and therapeutic importance of the drug has engendered development of assays for the quantification of PRG. A literature survey regarding PRG revealed that attempts were made to develop analytical methods for PRG using extractive spectrophotometric and spectroflurimetric (Armağan ö.,2009, Önal et al.,2009). LC method with precolumn derivatisation with marfeys reagent (A.S. Jadhav et al .,2007). HPLC analysis of PRG in human serum (Vermeij T A et al.,2004). Liquid chromatography - mass spectrophotometric (LC-MS-MS) (Walash M I et al., 2011, Vaidya VV et al., 2007, Zhang Y et al., 2008). Heteroaromatic analogs of pregabalin and its activity on mouse model (Schelkun RM et al., 2006). method had been reported. All of these methods are very expensive because these methods require long and tedious pretreatment of the samples and derivatisation for the analysis of PRG. There is no HPLC method without derivatisation for the analysis of PRG. So, there is need for the development of a HPLC method for the analysis of PRG. Hence, an attempt has been made to develop a simple, quick, specific, accurate efficient and selective method for the analysis of PRG in bulk and pharmaceutical formulations. This paper describes the Reverse Phase High Performance Liquid Chromatographic (RP-HPLC) method for estimation of PRG in bulk and 5-different pharmaceutical dosage forms. 


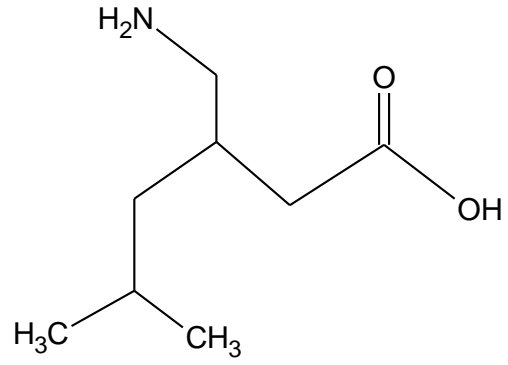

Fig. 1: Structure of Pregabalin.

\section{Experimental}

\subsection{Material and methods}

\subsubsection{Instruments}

Analysis by HPLC was performed using an isocratic system. i) The HPLC instrument was used model Younglin Acme-9000 with SP 930 D Pump, variable programmable UV detector, ii) Rheodyne injector with $20 \mu$ l fixed loop was used. iii) UV/VIS Spectrophotometer, Shimadzu, Model No UV 1800, iv) Digital pH - meter, Toshniwal instrument manufacture Pvt. Ltd (Mumbai, India). v) Chromatographic analysis was performed by using Autochro-3000 software. vi) The HPLC column used was a Reverse Phase varian C18, $5 \mu \mathrm{m}$ columns $(250 \mathrm{~mm} \times 4.6 \mathrm{~mm})$. vii) The mobile phase filtration unit was Ultipor N66, Nylon 6, 6 membranes (Pall Life Sciences, Mumbai, India).

\subsubsection{Chemicals and materials}

Pregabalin (Sun Pharmaceutical Industries, Jammu, India) used as a standard. Pharmaceutical formulations of Pregabalin such as Neugaba75 (Sun Pharmaceutical Industries, Mumbai, India), Pregastar-75 (Lupin ltd, Mumbai, India), Gabanext-75 (Nicholas Piramal India Ltd., Mumbai, India), Gabafit-75 (Glenmark Pharmaceutical Ltd., Mumbai, India), Maxgalin-75 (Sun Pharmaceutical Industries, Jammu, India) were containing labeled amount $75 \mathrm{mg}$ PRG were procured from a local pharmacy store. Methanol, Water HPLC grades were purchased from E-Merck, Mumbai, India. All other chemicals were of analytical grade and used without any further purification.

\subsection{Chromatographic system and conditions}

The proposed method was performed using a following chromatographic condition and are mentioned in Table 1.

Table 1: Chromatographic System and Conditions

\begin{tabular}{ll}
\hline Chromatographic mode & Chromatographic conditions \\
\hline HPLC system & Younglin (acme 9000) with software Autochro 3000 \\
Pump & SP 930 D \\
Detector & UV- detector \\
Column & C18, $5 \mu \mathrm{m}$ Reverse Phase varian $(250 \mathrm{x} 4.6)$ \\
Mobile phase & Methanol: Water $(95: 5)$ \\
Detection wavelength & $288 \mathrm{~nm}$ \\
Flow rate & $0.80 \mathrm{ml} / \mathrm{min}$ \\
Sample size & $20 \mu 1$ \\
Column temperature & Room temperature \\
Run time & $10 \mathrm{~min}$ \\
Filtration & By passing through a $0.45 \mu \mathrm{m}$ Ultipor filter and ultrasonication for 10 min. \\
Diluents & The mobile phase used as diluents. \\
\hline
\end{tabular}

\subsubsection{Optimization of chromatographic parameters}

Optimizations in HPLC is the process of finding a set of conditions that adequately enable the quantification of the analyze with acceptable accuracy, precision, sensitivity, specificity, cost, ease, and speed.

\subsubsection{Optimization of column and mobile phase strength}

It was achieved by monitoring varying columns and mobile systems. Silica columns such as a $\mu$ Bondapak column with different mobile phases did not give a suitable peak shape for analysis. On the other hand, C18, $5 \mu \mathrm{m}$ Reverse Phase varians (250 x 4.6) showed better results. For selection of mobile phase, various mobile phase compositions containing acetonitrile: methanol: water in different ratios was tried but the resolution was not found to be satisfactory. It was found that methanol: water gave satisfactory results with sharp well defined and acceptable peak parameters as compared to other mobile phases. Finally, the optimum composition of the mobile phase was selected as methanol: water (95: 5, V/V). Excellent chromatographic specificity with no interference from dosage form excipients was observed. Moreover, a suitable retention time for PRG was achieved. Typical chromatograms obtained from the standard solution of PRG, assay preparation of capsules. Under the chromatographic conditions described, PRG was well resolved and eluted at about 4.4167 min (Fig. 2), the total run time was within $10 \mathrm{~min}$. Good baseline resolution and peak shape can be observed. 


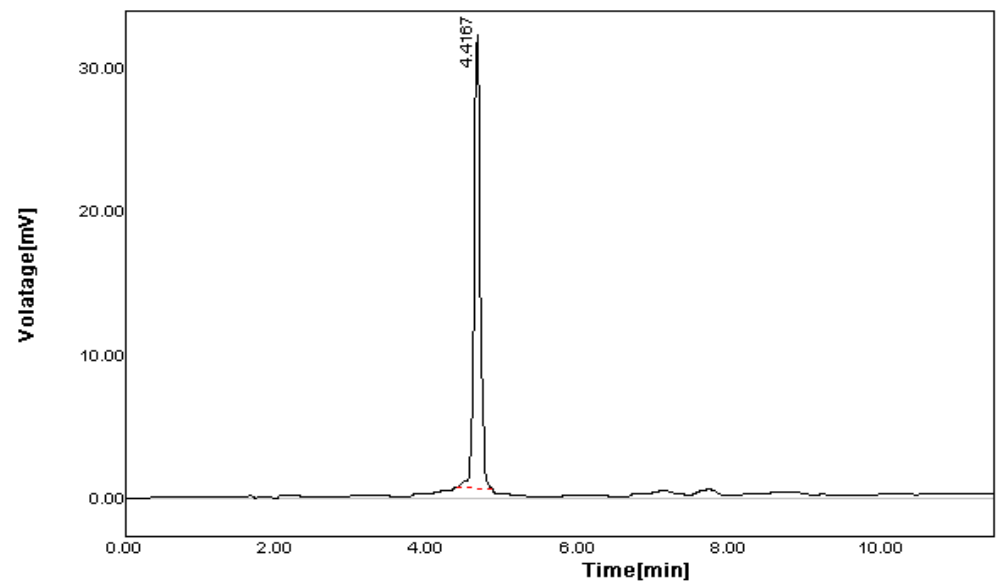

Fig. 2: Chromatogram of Pregabalin (PRG) Standard - R.T:4.4167.

\subsection{Optimization of detection of UV wavelength}

The sensitivity of HPLC method that uses UV detection depends upon proper selection of detection wavelength. An ideal wavelength is one that gives good response for the drugs that are to be detected. In the present study, by appropriate dilution of each standard stock solution with mobile phase, various concentrations of PRG were prepared separately. Each solution was scanned in the spectrum mode between the range of 200 to $400 \mathrm{~nm}$ and their spectra were seen. The wavelength selected for the analysis was $288 \mathrm{~nm}$ at which PRG showed significant absorbance.

\subsection{System suitability}

The system suitability of the proposed method was evaluated after spiking PRG. Following parameters mentioned in Table.2 was suitable for proposed method.

Table 2: System Suitability Parameters

\begin{tabular}{ll}
\hline Parameters & PRG $(15 \mu \mathrm{g} / \mathrm{ml})$ \\
\hline Retention time (min.) & 4.4167 \\
$\%$ area & 100 \\
Plates & 8128.1 \\
Tailing factor & 0.9324 \\
Asymmetry & 0.993 \\
\hline
\end{tabular}

*Average of nine determinations.

\subsection{Preparation of standard stock solutions}

Stock solution of PRG in the concentration of $1.0 \mathrm{mg} / \mathrm{ml}$ concentration was prepared in mobile phase. All solutions were shown to be stable during the period of study. Standard solutions of PRG (5.0, 10.0, 15.0, 20.0, 25.0, 30.0, 35.0 $\mu \mathrm{g} / \mathrm{ml})$ were prepared by subsequent dilution.

\subsection{Sample preparation for injection (capsule)}

20 capsules were weighed with or without caps and average weight was determined and finely powdered using mortar and pestle. Then ground material, which was equivalent to $25 \mathrm{mg}$ of PRG, was extracted using $10 \mathrm{ml}$ of mobile phase by ultrasonication and the volume was made up to $25 \mathrm{ml}$ by mobile phase. Then $10 \mathrm{ml}$ from the solution was taken and diluted with mobile phase to make up to $100 \mathrm{ml}$. The final solution ( $100 \mu \mathrm{g} / \mathrm{ml}$ of PRG) was filtered by $0.45 \mu \mathrm{m}$ nylon membrane filter by using injection filter.

\subsection{Preparation of mobile phase}

Methanol: water (95:5 v/v), Degassing ensures pump performance and improves detector response. Hence the mobile phase prepared was degassed by ultrasonication, so as to avoid the disturbances caused by dissolved gases. The degassed mobile phase was filtered through $0.45 \mu \mathrm{m}$ filter to avoid the column clogging due to smaller particles.

\subsection{Conditioning of the column}

Before a new run on HPLC, conditioning of the column was done by passing HPLC grade methanol at $1 \mathrm{ml} / \mathrm{min}$ flow rate for $30 \mathrm{~min}$ so as to remove the remains of the previous run. The double distilled water was run at flow rate of $1 \mathrm{ml} / \mathrm{min}$ for $1 \mathrm{~h}$, so as to remove water soluble impurities from on the column.

\subsection{Loading of mobile phase}

Filtered and degassed mobile phase was thus filled in the reservoir. Priming was done for each freshly prepared mobile phase.

\subsection{Baseline stabilization}


The detector was turned on for an hour before the actual run so as to obtain the stable UV light. The mobile phase run was started at required flow rate and the run was continued so as to obtain the stable baseline.

\section{Method validation}

\subsection{Calibration curve of pregabalin}

$50 \mathrm{mg}$ of PRG weighed and dissolved in $50 \mathrm{ml}$ of mobile phase. Then sonicated for $15 \mathrm{~min}$. Suitable dilutions of different concentrations using mobile phase were made from the standard stock solutions. The final solutions were filtered by $0.45 \mu \mathrm{m}$ nylon membrane filter by using injection filter. The linearity of the method was constructed for PRG reference standard solutions by plotting the concentrations of the compound versus peak area response. The linearity was evaluated by linear regression analysis, which was calculated by the least square regression method. PRG was found to be linear within range 5.0-45.0 $\mu \mathrm{g} / \mathrm{ml}$.

\subsection{Solution stability}

The stability of the reference PRG sample solutions at room temperature was evaluated with the help of HPLC systems.

\subsection{Specificity and selectivity}

The specificity and selectivity of the proposed method was evaluated by estimating the amount of pregabalin in the presence of common excipients such as magnesium stearate, starch, lactose, glucose, fructose and talc. The ability to separate all the compounds (excipients and substance) from PRG in the sample was demonstrated by assessing the resolution between the peaks corresponding to various substances.

\subsection{Recovery studies}

To study the accuracy, reproducibility and precision of the above method, recovery studies were carried out by addition of standard drug solution to pre-analyzed sample at three different levels. The method was evaluated within the linear range based on the analysis of PRG reference standard samples and pharmaceutical products at 20,30 and $35 \mu \mathrm{g} / \mathrm{ml}$. 5 independent analysis were performed at each concentration level within 1 day (intraday precision) as well as for three consecutive days (interday precision). Recovery experiments were carried out by standard addition method.

\subsection{Robustness Studies}

The robustness of a method is its ability to remain unaffected by small deliberate variations in the method parameters. The following changes in the optimum parameter values were examined, the flow rate of the mobile-phase and the proportion of the mobile phase.

\subsection{Limit of detection (LOD) and limit of quantification (LOQ)}

The limit of detection (LOD) and limit of quantitation (LOQ) of PRG was determined by calculating the signal-tonoise (S/N) ratio of 3:1 and 10:1, respectively according to International Conference on Harmonization guidelines.

\section{Results and discussion}

\subsection{Method development and optimization}

The applied chromatographic conditions permitted to a good resolution of PRG (30 $\left.\mu \mathrm{g} \mathrm{ml}^{-1}\right)$ in standard solution (fig. 2), and in sample solution (fig. 3). No drug deposition was observed during the analysis. The described method has been validated for the assay of PRG using parameters reported below (Mishra AK et al.,2010, United States of Pharmacopoeia 2000, P.D.Sethi 2001, Lloyd R et al., 2012).

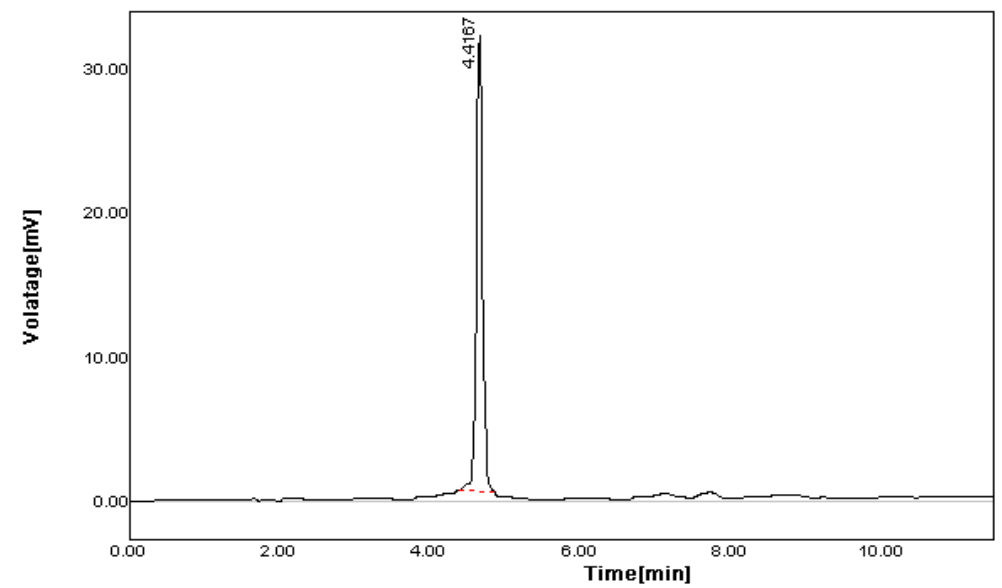

Fig. 2: Chromatogram of Pregabalin (PRG) Standard - R.T:4.4167. 


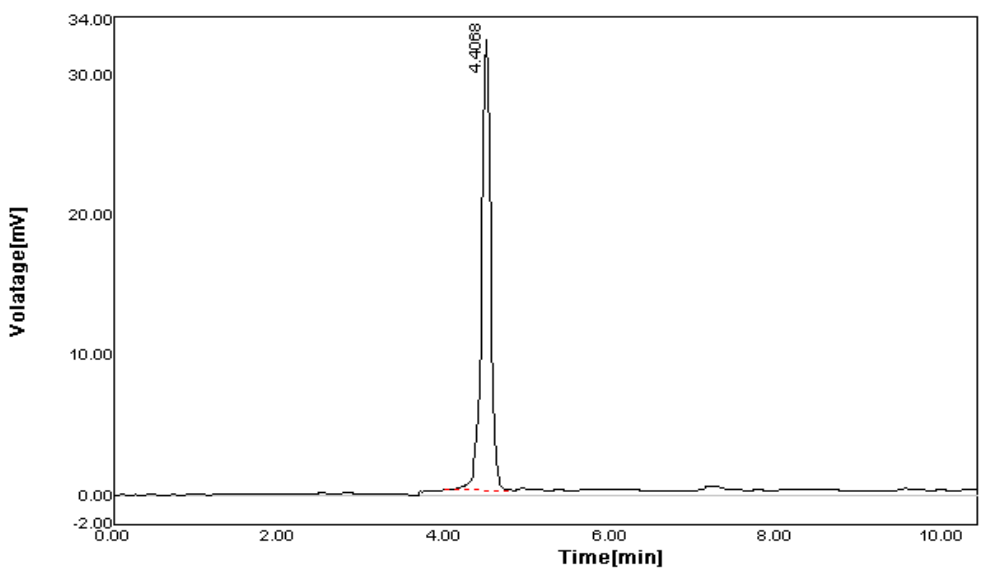

Fig. 3: Chromatogram of Pregabalin (PRG) Sample - R.T:4.4068.

\subsubsection{Linearity}

Under the optimum experimental conditions, the concentration vs peak area plot for the proposed method was found to be linear over the range of 5.0-45.0 $\mu \mathrm{g} / \mathrm{ml}$. The parameters for the regression analysis are given in Table.3. Linearity graph of different concentration of PRG shown in fig. 4

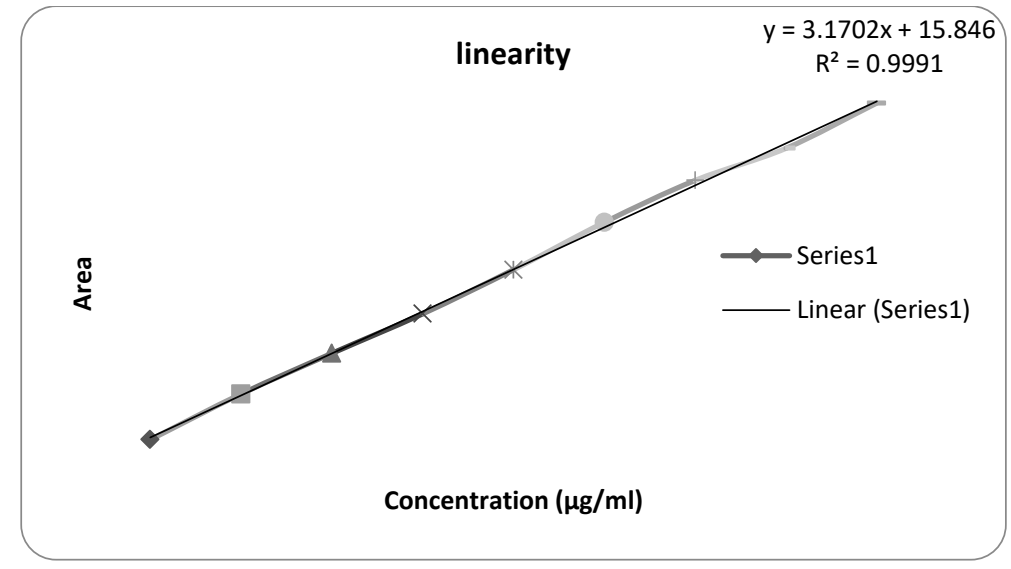

Fig. 4: Linearity of Pregabalin.

Table 3: Summary of Optical and Regression Analysis of the Calibration Curve for PRG

\begin{tabular}{ll}
\hline Statistical Parameters & Pregabalin \\
\hline Linearity range $(\mu \mathrm{g} / \mathrm{ml})$ & $5-45$ \\
Regression equation & $\mathrm{y}=\mathrm{mx}+\mathrm{c}=3.170 \mathrm{x}+15.84$ \\
Slope $(\mathrm{m})$ & 3.170 \\
Standard deviation of slope & 0.025 \\
Intercept(c) & 15.84 \\
Standard deviation of Intercept & 0.353 \\
Correlation coefficient $(\mathrm{r})$ & 0.999 \\
Limit of Detection $(\mathrm{LOD}), \mu \mathrm{g} / \mathrm{ml}$ & 0.37 \\
Limit of Quantization $(\mathrm{LOQ}), \mu \mathrm{g} / \mathrm{ml}$ & 1.124 \\
\hline
\end{tabular}

${ }^{\mathrm{a}}$ with respect to $\mathrm{y}=\mathrm{mx}+\mathrm{c}$, where $\mathrm{x}$ is the concentration in $\mu \mathrm{g} / \mathrm{ml}$, $\mathrm{Y}$ is the peak area.

\subsubsection{Precision}

The days of precision assays were carried out through replicate analysis $(\mathrm{n}=5)$ of PRG corresponding to $20.0,25.0,30.0 \mu \mathrm{g} / \mathrm{ml}$ for the proposed method in pure form (Table 4) and pharmaceutical formulations (Table-5 and 6). The interday precision was also evaluated through replicate analysis of the pure drug and pharmaceutical formulations samples for 5 consecutive days at the same concentration levels as used in the within day precision (Table 5 and 6). As can be seen from the Table 4 that the recovery and relative standard deviation (RSD, \%) by intraday and interday precision were in the ranges $98.88-100.062 \%, 0.114-0.245 \%$ and $98.92-100.008 \%, 0.065-0.34 \%$, respectively. As can be seen from Table 5 and Table 6 that that the recovery and RSD by intraday and interday precision were in the ranges $98.41-100.21 \% ; 0.028-0.502 \%$ and $98.07-100.2 \%, 0.01-1.49 \%$, respectively. The precision results are satisfactory.

Table 4: Summary of Accuracy and Precision Results of the Proposed Method for PRG in Pure Form

\begin{tabular}{|c|c|c|c|c|}
\hline Proposed methods & Pregabalin concentration, $(\mu \mathrm{g} / \mathrm{ml})$ & $\begin{array}{l}\text { Concentration Found } \pm \mathrm{SD}^{\mathrm{a}} \\
(\mu \mathrm{g} / \mathrm{ml})\end{array}$ & $\operatorname{RSD}(\%)$ & (\%) Recovery \\
\hline \multirow{3}{*}{ Intraday assay } & 20 & $20.008 \pm 0.049$ & 0.245 & 100.062 \\
\hline & 25 & $24.71 \pm 0.035$ & 0.141 & 98.88 \\
\hline & 30 & $29.73 \pm 0.033$ & 0.114 & 99.07 \\
\hline \multirow{3}{*}{ Interday assay } & 20 & $19.99 \pm 0.068$ & 0.34 & 100.008 \\
\hline & 25 & $24.72 \pm 0.0486$ & 0.196 & 98.92 \\
\hline & 30 & $29.74 \pm 0.0194$ & 0.065 & 99.15 \\
\hline
\end{tabular}

${ }^{\mathrm{a}}$ Mean for 5 independent analyses. 
Table 5: Intra-Day Variability of PRG in Different Pharmaceutical Formulations

\begin{tabular}{|c|c|c|c|c|}
\hline Pharmaceutical formulations & Pregabalin concentration, $(\mu \mathrm{g} / \mathrm{ml})$ & $\begin{array}{l}\text { Concentration Found } \pm \mathrm{SD}^{\mathrm{a}} \\
(\mu \mathrm{g} / \mathrm{ml})\end{array}$ & $\operatorname{RSD}(\%)$ & (\%) Recovery \\
\hline & 20 & $19.95 \pm 0.013$ & 0.067 & 99.79 \\
\hline \multirow[t]{3}{*}{ Neugaba-75 } & 25 & $24.68 \pm 0.007$ & 0.028 & 98.74 \\
\hline & 30 & $29.75 \pm 0.027$ & 0.090 & 99.18 \\
\hline & 20 & $20.03 \pm 0.039$ & 0.195 & 100.21 \\
\hline \multirow[t]{3}{*}{ Pregastar-75 } & 25 & $24.76 \pm 0.030$ & 0.123 & 99.06 \\
\hline & 30 & $29.75 \pm 0.020$ & 0.069 & 99.19 \\
\hline & 20 & $19.92 \pm 0.030$ & 0.150 & 99.62 \\
\hline \multirow[t]{3}{*}{ Gabanext-75 } & 25 & $24.59 \pm 0.120$ & 0.490 & 98.41 \\
\hline & 30 & $29.76 \pm 0.025$ & 0.086 & 99.20 \\
\hline & 20 & $19.96 \pm 0.047$ & 0.235 & 99.82 \\
\hline \multirow[t]{3}{*}{ Gabafit-75 } & 25 & $24.74 \pm 0.095$ & 0.384 & 98.98 \\
\hline & 30 & $29.77 \pm 0.019$ & 0.065 & 99.22 \\
\hline & 20 & $19.99 \pm 0.030$ & 0.154 & 99.97 \\
\hline \multirow[t]{2}{*}{ Maxgalin-75 } & 25 & $24.68 \pm 0.124$ & 0.502 & 98.73 \\
\hline & 30 & $29.76 \pm 0.019$ & 0.065 & 99.22 \\
\hline
\end{tabular}

${ }^{\mathrm{a}}$ Mean for 5 independent analyses.

Table 6: Intra-Day Variability of PRG in Different Pharmaceutical Formulations

\begin{tabular}{|c|c|c|c|c|}
\hline Pharmaceutical formulations & Pregabalin concentration $(\mu \mathrm{g} / \mathrm{ml})$ & $\begin{array}{l}\text { Concentration found } \pm \mathrm{SD}^{\mathrm{a}} \\
\left(\mu \mathrm{g} \mathrm{mL} \mathrm{m}^{-1}\right)\end{array}$ & $\operatorname{RSD}(\%)$ & (\%) Recovery \\
\hline \multirow{3}{*}{ Neugaba-75 } & 20 & $19.96 \pm 0.030$ & 0.150 & 99.85 \\
\hline & 25 & $24.77 \pm 0.033$ & 0.133 & 99.10 \\
\hline & 30 & $29.77 \pm 0.039$ & 0.131 & 99.24 \\
\hline \multirow{3}{*}{ Pregastar-75 } & 20 & $19.97 \pm 0.029$ & 0.145 & 99.88 \\
\hline & 25 & $24.89 \pm 0.373$ & 1.490 & 99.57 \\
\hline & 30 & $29.78 \pm 0.049$ & 0.165 & 99.27 \\
\hline \multirow{3}{*}{ Gabanext-75 } & 20 & $19.97 \pm 0.050$ & 0.250 & 99.84 \\
\hline & 25 & $24.61 \pm 0.061$ & 0.251 & 98.46 \\
\hline & 30 & $29.82 \pm 0.040$ & 0.135 & 99.43 \\
\hline \multirow{3}{*}{ Gabafit-75 } & 20 & $20.016 \pm 0.069$ & 0.344 & 100.2 \\
\hline & 25 & $24.77 \pm 0.035$ & 0.141 & 99.10 \\
\hline & 30 & $29.79 \pm 0.048$ & 0.161 & 99.31 \\
\hline \multirow{3}{*}{ Maxgalin-75 } & 20 & $19.96 \pm 0.033$ & 0.169 & 99.80 \\
\hline & 25 & $24.76 \pm 0.110$ & 0.447 & 98.07 \\
\hline & 30 & $29.76 \pm 0.030$ & 0.103 & 99.20 \\
\hline
\end{tabular}

${ }^{\mathrm{a}}$ Mean for 5 independent analyses.

\subsubsection{Accuracy}

The accuracy of the HPLC assay method was assessed by standard addition method. The results are reported in Table 7 (pure drug) and Table 8(capsule dosage forms) and the recoveries ranged from $99.03 \pm 0.116$ to $100.34 \pm 0.881 \%$ for pure drug and $99.29 \pm 0.45$ to $99.88 \pm 1.32$ for dosage forms, respectively. The proposed method results are satisfactorily accurate and precise.

Table 7: Recovery of PRG Using Proposed RP-HPLC Method

\begin{tabular}{lll}
\hline Amount of drug added, & Amount found, $\mu \mathrm{g} / \mathrm{ml},(\mathrm{n}=3)$ & $(\%)$ Recovery, $(\mathrm{n}=3)$ \\
$\mathrm{Mg} / \mathrm{ml}$ & Mean \pm S.D. & Mean \pm S.D. \\
\hline 20 & $20.06 \pm 0.179$ & $100.34 \pm 0.881$ \\
25 & $24.758 \pm 0.030$ & $99.033 \pm 0.116$ \\
30 & $29.73 \pm 0.149$ & $99.14 \pm 0.508$ \\
\hline
\end{tabular}

\subsection{Assay determination of pregabalin from its capsule formulations}

The assay results of samples at three different concentrations were also evaluated by the proposed method and the $\%$ recoveries mentioned as below in Table 8 .

Table 8: Mean \pm S.D. Amount of PRG in Capsule Dosage Forms by Using Proposed RP-HPLC Method

\begin{tabular}{llll}
\hline Capsule formulation & Labeled amount of drug, $(\mathrm{mg})$. & Mean \pm S.D., amount found, $\mu \mathrm{g},(\mathrm{n}=3)^{*}$ \\
\hline Neugaba-75 & 75 & $74.823 \pm 0.99$ & \% Recovery \\
Pregastar-75 & 75 & $74.819 \pm 0.75$ & $99.76 \pm 1.32$ \\
Gabanext-75 & 75 & $74.947 \pm 0.69$ & $99.76 \pm 1.01$ \\
Gabafit-75 & 75 & $74.465 \pm 0.38$ & $99.88 \pm 0.85$ \\
Maxgalin-75 & 75 & $74.472 \pm 0.33$ & $99.29 \pm 0.51$ \\
\hline
\end{tabular}

*Average of three different concentration levels.

\subsubsection{Limit of detection (LOD) and Limit of quantification (LOQ)}

LOD and LOQ was found to be 0.37 and $1.124 \mu \mathrm{g} / \mathrm{ml}$, respectively.

\subsubsection{Specificity and selectivity}

The specificity of the RP-HPLC method was determined by complete separation of PRG with parameters like retention time $\left(\mathrm{R}_{\mathrm{t}}\right)$, resolution (RS), and tailing factor (T). The peaks obtained for PRG were sharp and have clear baseline separation. Specificity parameters mentioned in Table 9. 
Table 9: Specificity Parameters

\begin{tabular}{ll}
\hline Parameters & Table 9: Specificity Parameters \\
\hline Tailing factor (T) & PRG*(Average \pm SD) \\
Resolution (RS) & $0.8761 \pm 0.08$ \\
Retention time (tR) & 0.0000 \\
\hline
\end{tabular}

*(Average $\pm \mathrm{SD})$ taken for five replicates.

\subsubsection{Robustness}

The robustness of the method relative to each operational parameter was checked and investigated. The influences of small changes in the mobile phase composition were studied to determine the robustness of the method, such as the changes in peak area and retention time. The results are summarized in Table 10. The robustness of the method was also assessed by analyzing the active PRG in pharmaceutical formulations. The reference standard sample solution containing $30.0 \mu \mathrm{g} / \mathrm{ml}$ of the drug was assayed and indicating that the proposed method is robust.

Table 10: Robustness Studies

\begin{tabular}{lll}
\hline Mobile Phase Composition & Retention Time (tR) \\
\hline Methanol: water $(85: 15), 0.7 \mu \mathrm{g} / \mathrm{ml}$ & 4.5167 \\
Methanol: water $(90: 10), 0.8 \mu \mathrm{g} / \mathrm{ml}$ & 4.4000 \\
Methanol: water $(75: 25), 1 \mu \mathrm{g} / \mathrm{ml}$ & 3.7833 \\
Methanol: water $(95: 5), 1.2 \mu \mathrm{g} / \mathrm{ml}$ & 3.4000 \\
Methanol: water: Acetonitrile $(90: 5: 5), 1.0 \mu \mathrm{g} / \mathrm{ml}$ & 3.2333 \\
Methanol: water: Acetonitrile $(85: 10: 5), 0.7 \mu \mathrm{g} / \mathrm{ml}$ & 4.5000 \\
\hline
\end{tabular}

\subsubsection{Solution stability}

The solution stability was ascertained from HPLC peak area of reference standard samples. The peak area was obtained at 4.4167 min retention time with a UV detector of wavelength of $288 \mathrm{~nm}$ (shimadzu, UV-1800). The standard sample solutions were kept at room temperature for 5 days, it was observed that there was no change in peak area of these solutions.

\section{Conclusion}

The proposed RP-HPLC method has been evaluated over the linearity, precision, accuracy, stability, specificity and proved to be convenient and effective for the quality control of PRG in bulk and pharmaceutical formulations. The major advantages of this method include short retention time, without derivatisation with other reagent, stability of the solution, no need for prior separation or purification before analysis, and the applicability of a common HPLC system (Isocratic system, UVdetector). The short chromatographic time makes this method suitable for the processing of multiple samples in a limited period of time. The method shows no interference from common excipients. Thus, proposed method is rapid, selective, simple, cost effective, fast and efficient. Finally, since no pharmacopoeial method for determination of PRG in bulk and pharmaceutical formulations have been reported yet, the proposed method could be useful and suitable for the determination of PRG in bulk and pharmaceutical formulations.

\section{Acknowledgement}

The authors are grateful to Professor Mr. Sachin Kokil, Bharati Vidyapeeth College of pharmacy, Kolhapur, for their support and encouragement.

\section{References}

[1] ARMAĞAN Ö. Development and validation of selective spectrophotometric methods for the determination of pregabalin in pharmaceutical preparation. Chinese Journal of Chemistry. 2009 Apr;27(4):781-6. https://doi.org/10.1002/cjoc.200990130.

[2] Önal A, Sagirli O. Spectrophotometric and spectrofluorimetric methods for the determination of pregabalin in bulk and pharmaceutical preparation. Spectrochimica Acta Part A: Molecular and Biomolecular Spectroscopy. 2009 Feb 1;72(1):68-71. https://doi.org/10.1016/j.saa.2008.08.009.

[3] Jadhav AS, Pathare DB, Shingare MS. Validated enantioselective LC method, with precolumn derivatization with Marfey's reagent, for analysis of the antiepileptic drug pregabalin in bulk drug samples. Chromatographia. 2007 Feb 1;65(3-4):253-6. https://doi.org/10.1365/s10337-006-0152-z.

[4] Vermeij TA, Edelbroek PM. Simultaneous high-performance liquid chromatographic analysis of pregabalin, gabapentin and vigabatrin in human serum by precolumn derivatization with o-phtaldialdehyde and fluorescence detection. Journal of Chromatography B. 2004 Oct 25;810(2):297-303. https://doi.org/10.1016/S1570-0232(04)00662-2.

[5] Walash MI, Belal FF, El-Enany NM, El-Maghrabey MH. Utility of certain nucleophilic aromatic substitution reactions for the assay of pregabalin in capsules. Chemistry Central Journal. 2011 Dec;5(1):36. https://doi.org/10.1186/1752-153X-5-36.

[6] Vaidya VV, Yetal SM, Roy SM, Gomes NA, Joshi SS. LC-MS-MS Determination of pregabalin in human plasma. Chromatographia. 2007 Dec 1;66(11-12):925-8. https://doi.org/10.1365/s10337-007-0430-4.

[7] Zhang Y, Holliman C, Tang D, Fast D, Michael S. Development and validation of a direct enantiomeric separation of pregabalin to support isolated perfused rat kidney studies. Journal of Chromatography B. 2008 Nov 1;875(1):148-53. https://doi.org/10.1016/j.jchromb.2008.07.042.

[8] Schelkun RM, Yuen PW, Wustrow DJ, Kinsora J, Su TZ, Vartanian MG. Heteroaromatic side-chain analogs of pregabalin. Bioorganic \& medicinal chemistry letters. 2006 May 1;16(9):2329-32. https://doi.org/10.1016/j.bmcl.2005.06.090.

[9] Mishra AK, Kumar M, Mishra A, Verma A, Chattopadhyay P. Validated UV spectroscopic method for estimation of salbutamol from tablet formulations. Archives of Applied Science Research. 2010;2(3):207-11.

[10] Snyder LR, Kirkland JJ, Glajch JL. Practical HPLC method development. John Wiley \& Sons; 2012 Dec 3. 